\title{
Phantom Tasks and Invisible Rubric: The Challenges of Remixing Learning Objects in the Wild
}

\author{
David E. Millard ${ }^{1}$, Yvonne Howard ${ }^{1}$, Patrick McSweeney ${ }^{1}$, Miguel Arrebola ${ }^{3}$, \\ Kate Borthwick ${ }^{2}$, Stavroula Varella ${ }^{3}$ \\ ${ }^{1}$ School of ECS, University of Southampton, \{dem, ymh, pm5 $\}$ ecs.soton.ac.uk, \\ ${ }^{2}$ School of Humanities, University of Southampton, K.Borthwick@ soton.ac.uk \\ ${ }^{3}$ School of Languages and Area Studies, University of Portsmouth, \{Miguel.Arrebola, \\ Stavroula.Varella\}@ port.ac.uk
}

\begin{abstract}
Learning Objects are atomic packages of learning content with associated activities that can be reused in different contexts. However traditional Learning Objects can be complex and expensive to produce, and as a result there are relatively few of these available. In this paper we describe our work to create a lightweight repository for the language-learning domain, called the Language Box, where teachers and students can share their everyday resources and remix and extend each others content using collections and activities to create new Learning Objects more easily. However, in our interactions with the community we have discovered that practitioners find it difficult to abstract their teaching materials from their teaching activities and experiences; this results in Phantom Tasks and Invisible Rubrics that can make it difficult for other practitioners to reuse their content and build new Learning Objects.
\end{abstract}

Keywords: Open Educational Resources, Remixing, Learning Objects

\section{Introduction}

Teachers and Lecturers rely on good teaching resources to support their teaching activities. Many of these resources are created to support specific courses at specific institutions, and for many years researchers have been exploring ways in which teachers could share the effort of creating resources, by building reusable Learning Objects that wrap up a set of complementary resources in an atomic package [4].

Learning Objects are typically deployed through a Virtual Learning Environment (VLE), and as a result are relatively heavyweight, with sophisticated internal structure and meta-data that is designed for experts. But increasingly we are seeing a trend of practitioners rejecting the formality and overhead of using a VLE, and turning to resources in-the-wild, content that is online and shared through public sites such as Wikipedia, YouTube and iTunes.

Unlike traditional Learning Objects, these resources are relatively simple - often single files with content that is contextualized to its original use (for example, slides that are explicitly part of a larger course). Many institutions, such as MIT in the USA 
and the Open University in the UK, are embracing this more open lightweight approach, and the term Open Educational Resources (OER) has emerged to refer to this type of shared content [2].

We have been involved in developing a repository for OER content for the Language Learning community. The Language Box is a lightweight repository based on the EPrints platform; it encourages users to share their everyday teaching resources without the overhead of complex meta-data or structures [11].

The Language Box includes a number of mechanisms to support the reuse and remixing of content, by allowing users to create and share collections of resources, and augment each other's materials with new activities. We hoped that we would see new types of lightweight Learning Objects emerge from community interaction, as users grouped together useful content with instructions for its use. However, although the mechanisms are well received in workshops, they are underused in practice, and we have seen users struggle to express their resources in anything other than the most simplistic way.

In this paper we describe how the Language Box supports resource reuse and remixing, and explore why users seem unable to take advantage of these systems. Section 2 puts our work in context with other efforts to support reuse of educational resources. Section 3 describes the history and design behind the Language Box and Section 4 presents the data model that underpins our simple remixing facility. Section 5 explores why users have difficulty abstracting their resources into reusable parts, and we introduce Phantom Activities and Invisible Rubrics as examples of this problem. Finally Section 6 concludes the paper and describes how we plan to address these issues in future Language Box updates.

\section{Background}

The IEEE describes a Learning Object as "any entity, digital or non-digital, that may be used for learning, education or training" [8]. This broad definition is supported by formal specifications of how to describe digital Learning Objects in the IEEE LOM standard [7].

Despite interest from educational and educational research communities Learning Objects have not been as successful as their proponents hoped. Learning Objects have been criticized for using complex terminology that is not meaningful to ordinary practitioners [12], and their sophisticated structure (for example, using packages with manifests to describe their contents) has also meant that ordinary practitioners do not usually have the skills to create a formal Learning Object that could be deployed on a VLE [1].

Those Learning Objects that have been created can be difficult to find, Learning Object repositories are a way of storing Learning Objects in an open and accessible way [13] so that they can be easily browsed and deployed [14]. Research on Learning Object repositories has explored how they might be standardized [5], and also how graphical browsing interfaces might help users find Learning Objects that match their requirements more quickly [9]. 
As well as formal Learning Objects, teaching and learning repositories can deal with tutor created content, and shared resources that have been discovered on the wider web [16]. For example, Merlot is a repository of several thousand online resources that have been peer-reviewed for quality [15].

Some repositories allow their users to create virtual structures to help manage the Learning Objects, for example the ResourceCenter allows users to collect resources together into SCORM compliant structures [6]. However, the Web has evolved a much more lightweight remix culture, that encourages users to be flexible with authorship and experiment with each others content [3], it has been argued that this attitude could be successfully extended to teaching materials, and might help create a culture of sharing that is more successful that the Learning Object economy [10]

\section{The Language Box}

The Language Box is an attempt to re-imagine a Learning Object repository in a Web 2.0 way. We have embraced a lightweight sharing and remixing approach and have opted for a simple repository that allowed users to store their everyday materials, view them online in a browser, leave feedback and suggestions, and use simple collection and extension mechanisms to help evolve new resources over time.

\subsection{Motivation and History}

We have been involved in creating teaching and learning repositories for several years, our early work focused on providing a repository for Learning Objects for the Language Teaching Community. This repository, which was called CLARE, was evaluated with teachers and lecturers, and although they appreciated the repository as a way of obtaining learning resources, it was clear that there was a mismatch between the sophistication of Learning Objects and their own digital assets and skills.

Our workshops highlighted four key problems with the Learning Object approach:

1. Complex Metadata - the complexity of the deposit process was a significant barrier to practitioners, the problem is in the need to specify a large number of meta-data fields. CLARE used a variation of the UK LOM Core, a schema which includes 25 required fields (and a further 27 recommended fields)[7]. It was clear that while professional Learning Object developers were prepared to take the time to understand and complete the schema, everyday sharers would not be.

2. Unfamiliar Terms - LOM also uses pedagogical terms that are sometimes unfamiliar to practitioners. For example, the schema would talk about scaffolding, but teachers would talk about supporting materials. An everyday repository needs to use simple, clear terms that relate to practice.

3. Content Packaging - CLARE made Learning Objects available as compressed zip files, containing an XML manifest. Most of the teachers in our workshops had encountered compressed zip files before, but many did 
not really understand what they were, or how to open them. Those that did were confused by the internal structure of the Learning Object and baffled by the XML manifest. Teachers expect the materials downloaded from a repository to come in a familiar format, which matches the digital resources that they create themselves.

4. Lack of Contextual Information - despite the amount of meta-data on each Learning object they still lack contextual information about how they have been used by other practitioners. Unstructured feedback from other users, such as simple comments, is far more important to teachers and lecturers, in terms of helping them decide if a resource will be useful, than the formal descriptions created by the Learning Object author.

We concluded that the requirement for simplicity outweighed other needs, such as cross-indexing and quality control. When we revised CLARE into the Language Box, we wanted to make it as cheap as possible to add materials to the repository, and wanted complexity and detail to emerge through use, rather than being specified up front.

\subsection{Design Methodology}

When designing the Language Box we turned to popular Web 2.0 sharing sites such as YouTube and Flickr for inspiration. We concluded that whereas traditional repositories (as typically used for research publications) are about Archiving content, a sharing-style repository is more about Hosting materials online with the minimum overhead to the user (such as YouTube's inline video tool), allowing users to Organise their own materials alongside others (such as Flickr's albums) and creating a Community of users (through profiles, tagging, statistics and commentary mechanisms that can be found on both sites).

We found it interesting that Sharing is not the key service, users place content online with a specific audience in mind, but often this is an act of communication rather than sharing (for example, someone uploading holiday photographs may be trying to reach their extended family, they are not placing photos online for others to repurpose). Sharing in the greater altruistic sense seems to be a side effect of more pragmatic selfish motives.

We listed three key objectives for the Language Box based on the services of Hosting, Organisation and Community:

1. Hosting: Ability to preview online

2. Organisation: Ability to create public collections and extensions

3. Community: More prominent user presence through profiles

We concentrated on simple atomic resources with no content packaging, and used a minimum set of manual metadata to describe them (only the title is a required field). Because we have an inline preview tool, users can use resources from within their web browser without having to download them. We also encourage users to make their materials as public as possible through the use of Creative Commons licenses. 


\subsection{Implementation}

The Language Box is based on the EPrints repository platform, heavily modified through client-side Javascript and a Flash-based preview tool (Figure 1).

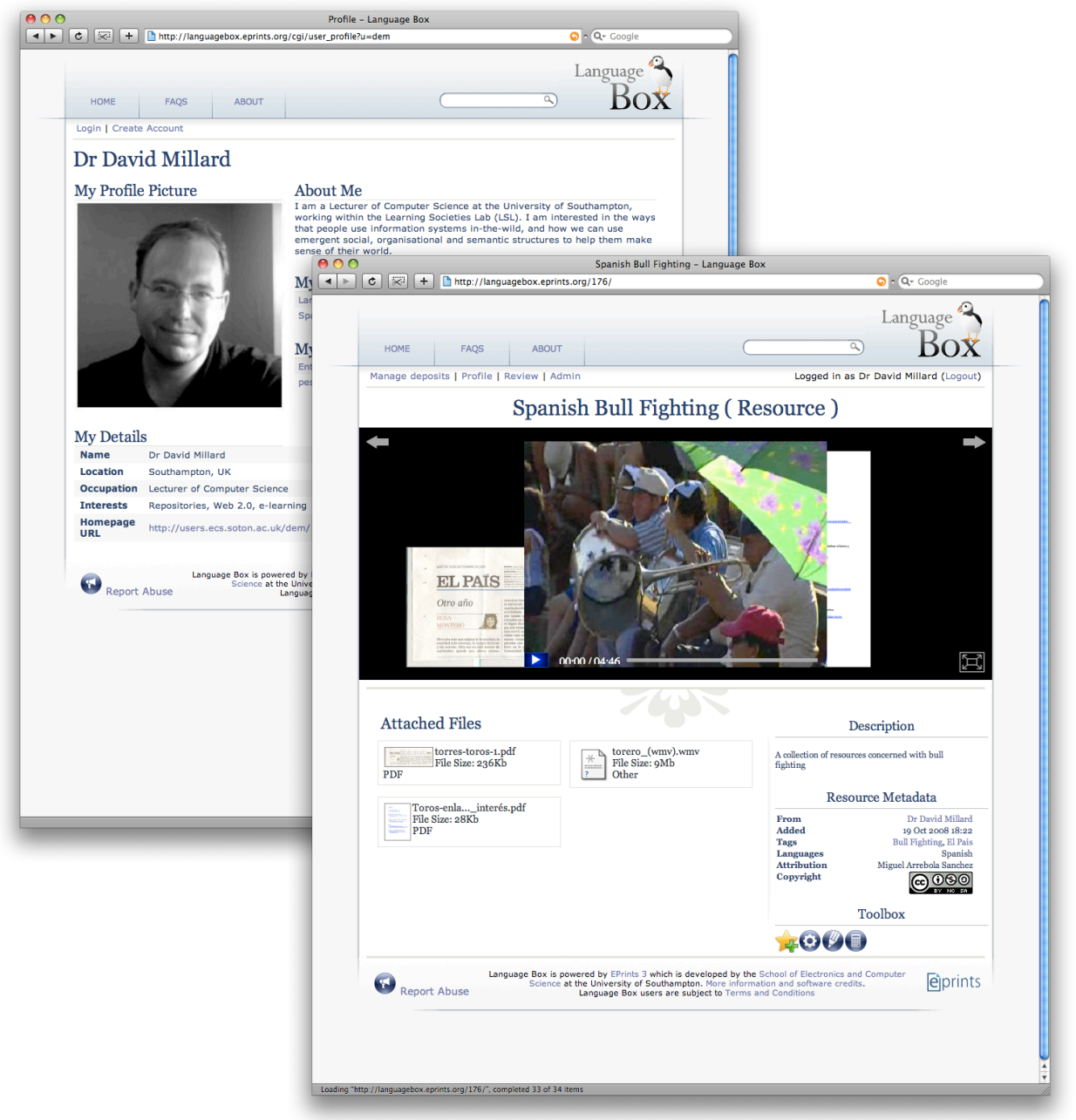

Fig. 1. The Language Box Profile Page (left) helps create identity, and provides a central page for users to access all of their uploads. The Resource Page (right) allows users to view the metadata and download files, but also includes a cover flow style preview tool for inline viewing of multimedia formats (for example, video, audio, slides and documents). 


\section{Simple Remixing - The Language Box Model}

As part of our efforts to support organisation and build community we wanted to include some simple remixing tools into the Language Box. Some sharing sites, most notably video editing sites such as Jumpcut ${ }^{1}$, include quite sophisticated remixing tools that allow audio, video and images to be layered together in complex ways; for the Language Box we needed something that was simpler and more granular, but which fitted the sort of pedagogical activities that our users would be interested in.

Early in our project we undertook an extensive co-design process with a number of language teachers and e-learning specialists in order to create an appropriate remix model. Very early on we identified the need for Activities, instructions on how to use a resource for a particular teaching or learning task. Initially we modeled these as a type of comment, but it quickly became apparent that many teachers see activities not as ethereal instructions, but as concrete items in their own right, often with files directly related to them (for example in the form of a task sheet). As a result in our later iterations Activities became explicit items in the repository with their own page. This way they can have additional files uploaded to support them, and their URL can be circulated independently of the resource that they are based on.

Figure 2 shows the data model that came out of this process. It consists of three types of EPrint (objects in the repository): Resources, Activities and Collections.

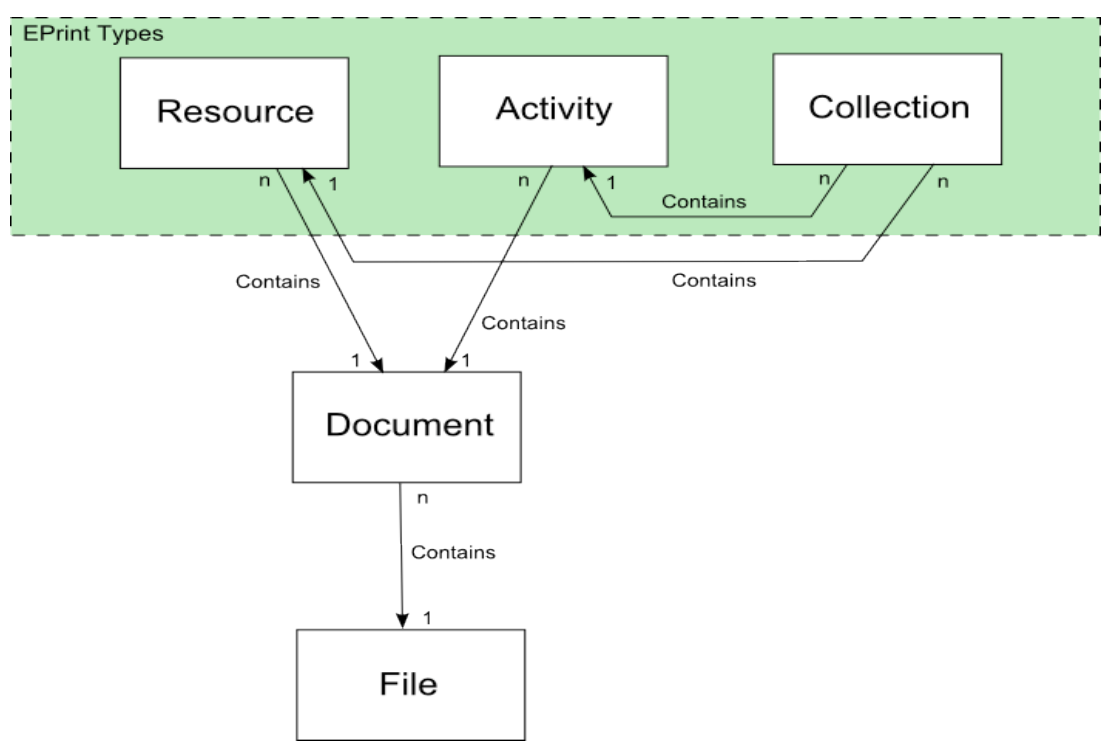

Fig. 2. The Language Box Data Model. The top three types are specializations of an EPrint, (a deposit in the repository with its own metadata and page); they represent the three different types of deposit supported by the repository.

\footnotetext{
${ }^{1}$ Jumpcut website: http://www.jumpcut.com/
} 
The key item in the repository is a Resource; this is an atomic unit of teaching material such as a set of slides or a video. EPrints uses a Document object to represent component files such as HTML with CSS, but this is invisible to users. Resources can include multiple documents if those files should be considered together, for example the text of a newspaper article and accompanying scanned copy. Resources contain no information about how they should be used in teaching or learning. This makes it easy to repurpose Resources without modifying them.

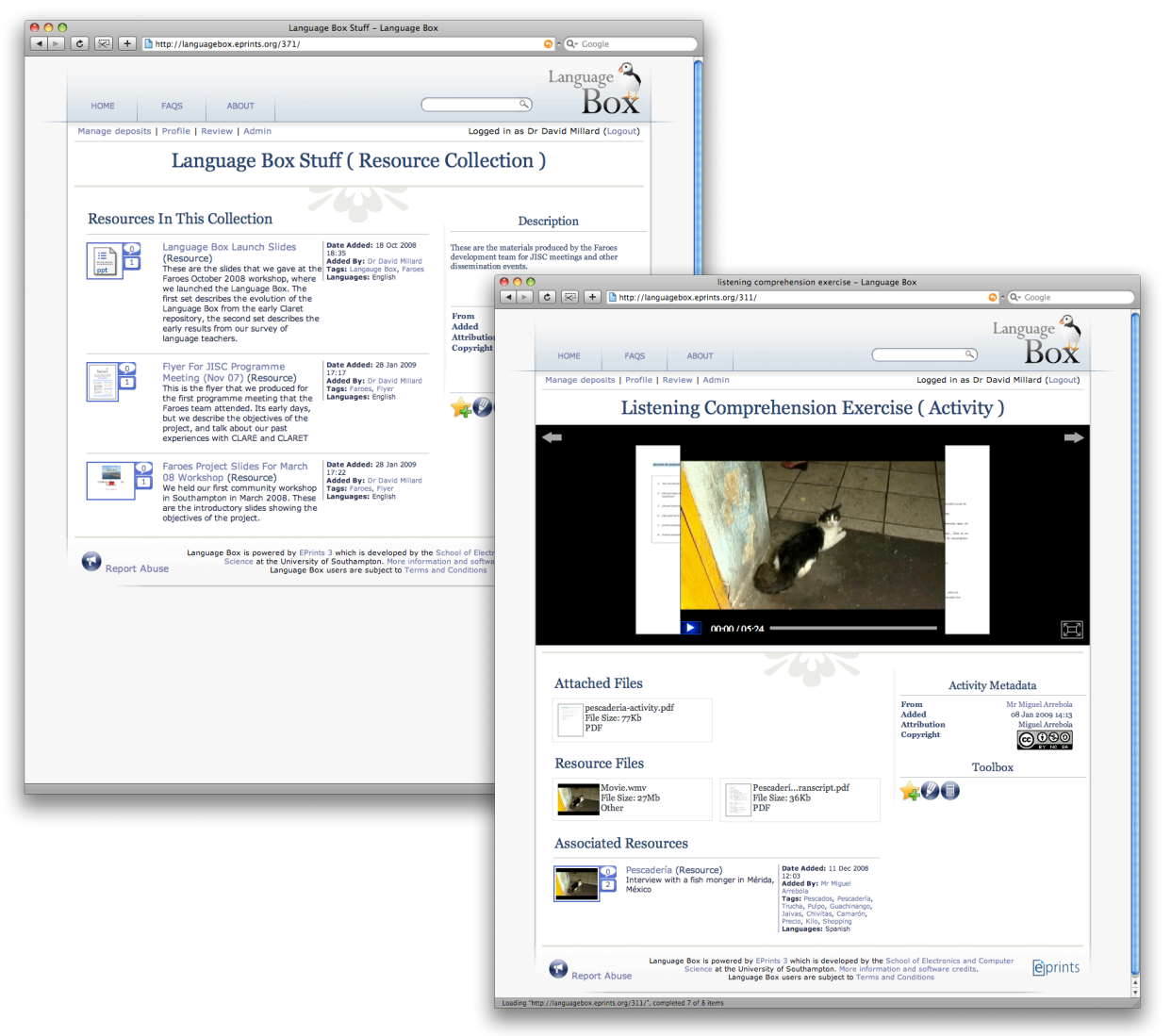

Fig. 3. A Collection page on the Language Box (left), and an Activity page (right). At the bottom of the Activity page there is a link through to the original resource.

Resources can be extended with an Activity (shown in Figure 3). An Activity is a set of instructions (possibly in additional files) that describe one potential use of a specific Resource. For example: "Read the article and then answer the questions on this worksheet". Resources can have multiple Activities, and while Resources can only be edited by their authors, anyone can annotate a Resource with their own Activity. Activities have their own page in the repository that is independent from (although linked to) the original resource. This makes it possible for teachers to create pages in the repository for their own activities, even if those activities are based on someone else's resources. 
Finally, Resources and Activities can be brought together into a Collection (also shown in Figure 3). Users can create collections containing both their own material and items uploaded by others. The Language Box doesn't make any assumptions about how a user will use a collection, for example, it could be used to gather together useful items on a topic, or to organize resources for a course.
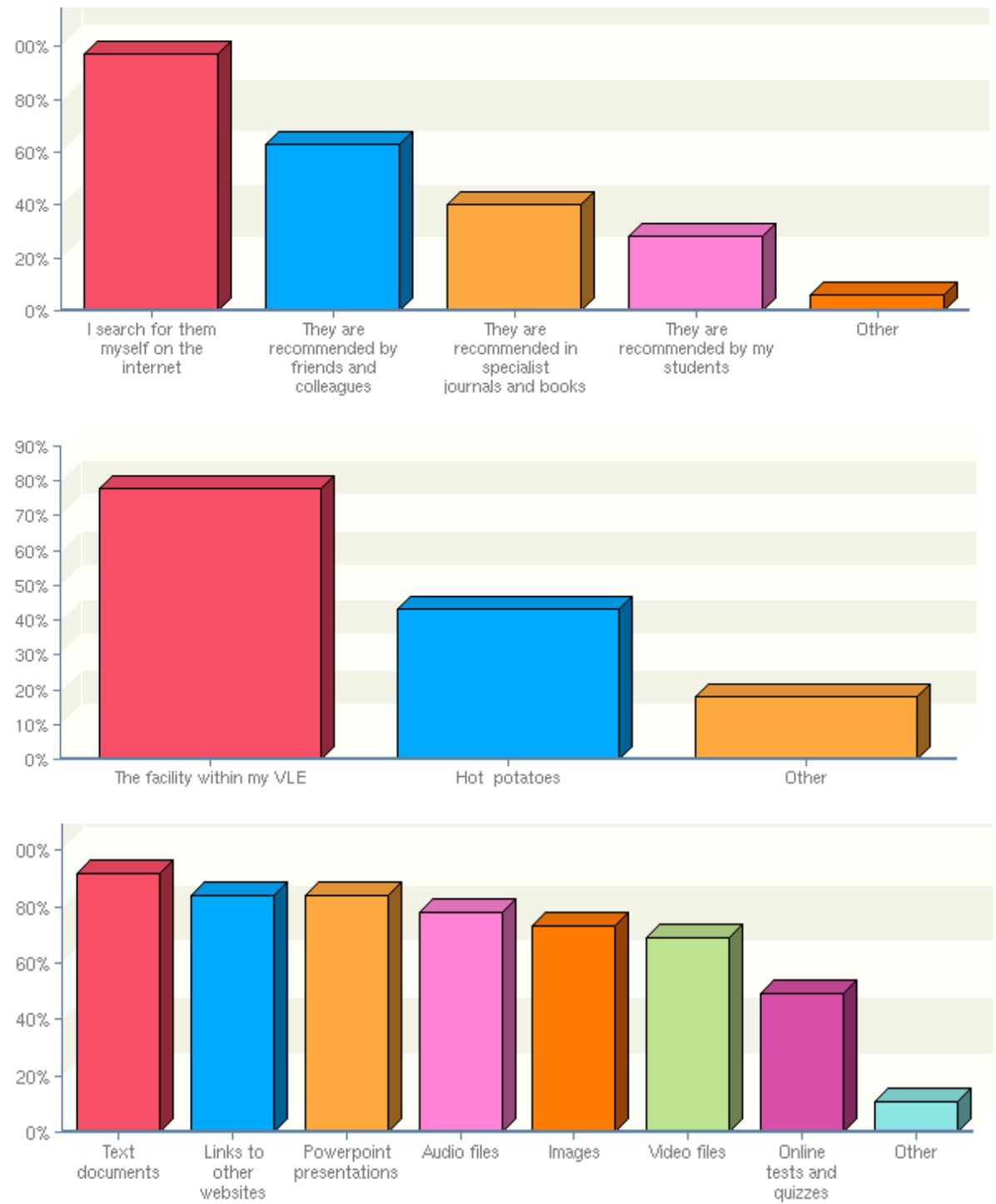

Fig. 4. Initial survey results. Top: Where do practitioners find resources? Middle: How do practitioners create new activities? Bottom: What type of resources do they use? 


\section{Challenges for Practitioners}

We have held a number of workshops with members of the Language Teaching community in order to understand their current use of technology, their attitudes to it, and their responses to the Language Box. Despite a high level of technology use we have discovered that many practitioners are not used to managing their own digital assets, and find it difficult to adapt their practices for the online world.

\subsection{Digital Resource Use}

At the beginning of our project we surveyed the community in order to explore their current levels of technology use, we sent out a questionnaire to over a thousand practitioners and received 201 responses. Figure 4 shows some of our initial findings. We discovered that practitioners are very proactive in locating resources for themselves, with less than half relying on traditional sources such as books to direct them. They also used a wide range of multimedia types - this may be because of the nature of language teaching, where video and audio sources have always been important. Most practitioners also generated digital activities themselves; most used the VLE, but many also used Hot Potatoes.

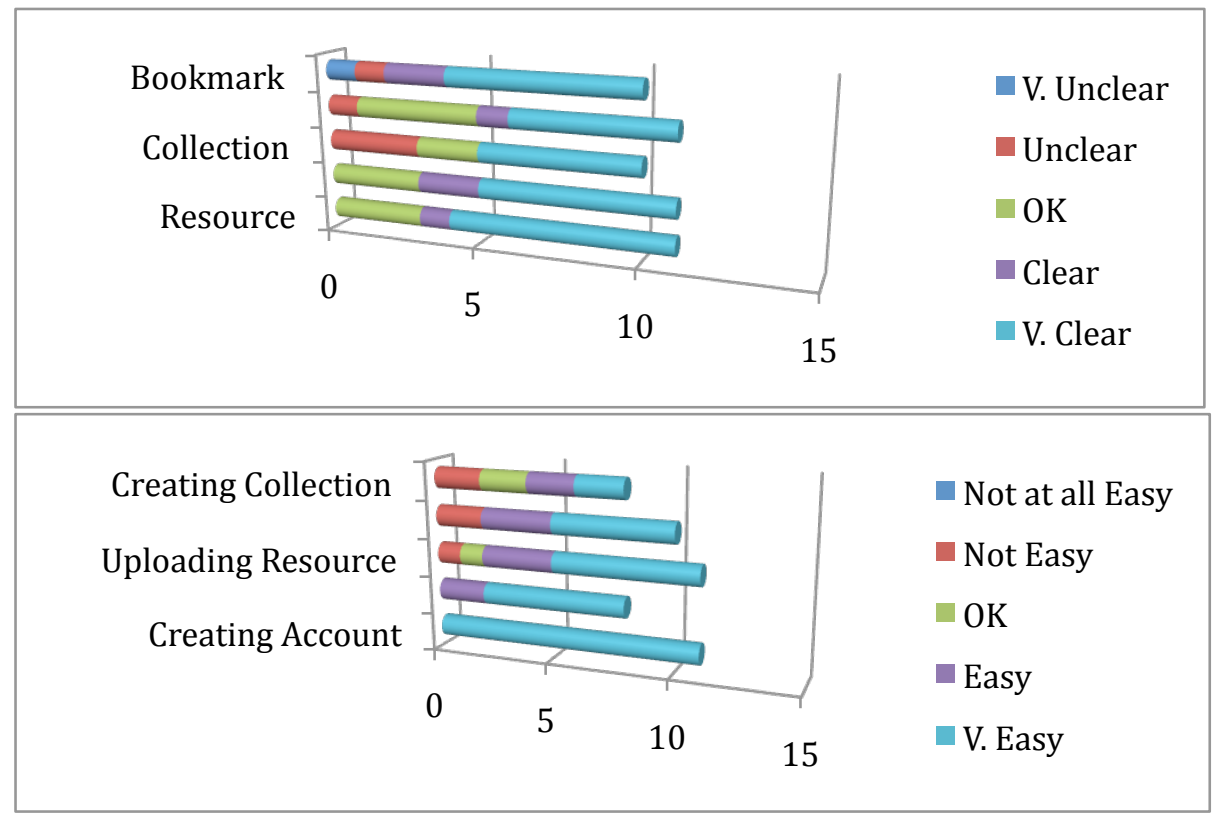

Fig. 5. Usability Evaluation. Top: How clear did users find the terms used in the Language Box? Bottom: How easy was it to do various activities in the Language Box?

This made us hopeful that the users of the Language Box would be able to use the facilities we had provided to create activities based on other people's content. 
However, although we have had 200 deposits in the first few months after the Language Box went live, users have only created 22 activities. In all cases these activities were created by the same person who deposited the original resource, so we have no instances of a user creating an Activity based on someone else's deposit.

At a later workshop we surveyed the attendees in order to find out if the problem lay with the technology, the results are shown in Figure 5. Although this was only a indicative usability study (11 participants) we discovered that users were mostly happy with our use of terms (with all users rating Activity and Resource between OK and Very Clear), and that most users (8/10) found that creating an Activity was Easy or Very Easy. From this it was clear that the issue was not with usability.

\subsection{Resources vs. Activities}

At our most recent workshop we spent some time discussing the issue of Activity creation with participants, we suspected that the issue may be because participants were unable to decide whether something should be uploaded as a resource or an activity, so we ran a small exercise (12 participants) to see if they could match up materials that they might use with our terms. The results are shown in Table 1.

If it were clear how to classify activities then we would expect to see all 12 practitioners classifying in the same way, but instead we see a great deal of variation. We followed the questionnaire with a discussion session in order to understand the reasoning behind some of their choices. We discovered that the problem lies in practitioners' ability to abstract activities from the resources that they use.

\subsubsection{Phantom Tasks}

A key issue is that many resources have activities that are not specified in an explicit way, but are heavily implied by the resource, we call these Phantom Tasks. This is clearest in items 1-3 of Table 2, which are straightforward resources with no explicit tasks. Despite this several practitioners identified them as both an activity and a resource and later told us that this was because the resource implied an activity - for example, a video of a conversation implies a simple comprehension task.

Phantom Tasks exist for many types of resources, but for resources that strongly imply a task they can become overpowering, and become confused with the resource itself. For example, item 4 is a Hot Potatoes page, strictly speaking this is a resource that could be used in a number of different activities, but because of its structure it strongly implies that students should work through the exercises on the page on their own (perhaps as a revision or personal study task) and thus most of our participants thought it was an activity.

\subsubsection{Invisible Rubrics}

Another problem is that sometimes the activity part of a resource - the instructions on how to use it - can be so slight that practitioners do not see it as a separate item; we call these Invisible Rubrics. For example, item 7 is an exam paper, strictly speaking this is a set of questions (the resource) and a rubric (the activity), but practitioners do 
not perceive the rubric as an independent object, and are therefore confused about how the exam paper should be handled in the system.

In general we found that unless the activity had a file associated with it (such as a class handout in the form of a PDF) it was likely that it would be invisible to practitioners. For some resources this means that invisible rubrics become phantom tasks; for example, practitioners would upload an exam paper as a resource, but ignore the rubric (or include it in the exam paper) because the exam questions on its own strongly implies that it should be used for formal assessment or revision.

Table 1. Classification of Items by Practitioners as either a Resource or an Activity.

\begin{tabular}{|c|c|c|c|c|c|}
\hline No. & Description of Item & Resource & Activity & Both & Other \\
\hline 1 & $\begin{array}{l}\text { Video of a conversation between two } \\
\text { French students about university life }\end{array}$ & 10 & & 2 & \\
\hline 2 & A selection of images of Polish food & 11 & & 1 & \\
\hline 3 & $\begin{array}{l}\text { A transcript of an audio recording of a } \\
\text { lecture on Spanish history }\end{array}$ & 9 & & 2 & $\begin{array}{l}1 \text { (Resource } \\
\text { Exploitation) }\end{array}$ \\
\hline 4 & $\begin{array}{l}\text { A Hot Potatoes activity (html web page) } \\
\text { which practices an element of grammar }\end{array}$ & & 9 & 3 & \\
\hline 5 & $\begin{array}{l}\text { A powerpoint file which accompanied a } \\
\text { lecture on British politics }\end{array}$ & 12 & & & \\
\hline 6 & $\begin{array}{l}\text { A handout explaining how to write a } \\
\text { literature review, including some } \\
\text { revision questions }\end{array}$ & 6 & 2 & 4 & \\
\hline 7 & $\begin{array}{l}\text { A set of exam questions for first-year } \\
\text { Italian }\end{array}$ & 4 & 1 & 7 & \\
\hline 8 & $\begin{array}{l}\text { A set of guidelines on how to produce a } \\
\text { podcast }\end{array}$ & 7 & 1 & 3 & 1 (Reference) \\
\hline 9 & $\begin{array}{l}\text { Some teaching notes to accompany a } \\
\text { video of bull-fighting in Spain, which } \\
\text { you found on the Language Box }\end{array}$ & 7 & 1 & 3 & 1 \\
\hline 10 & $\begin{array}{l}\text { An audio file containing discussion } \\
\text { questions for a seminar on linguistics }\end{array}$ & 6 & 3 & 3 & \\
\hline 11 & $\begin{array}{l}\text { A quiz sheet on the environment, } \\
\text { inspired by a powerpoint file you found } \\
\text { on Language Box }\end{array}$ & 2 & 5 & 5 & \\
\hline 12 & $\begin{array}{l}\text { A reading list for a first-year Russian } \\
\text { course }\end{array}$ & 9 & 1 & 1 & 1 \\
\hline 13 & $\begin{array}{l}\text { A poster advertising a Language- } \\
\text { learning café }\end{array}$ & 7 & & 1 & 4 (advert) \\
\hline 14 & $\begin{array}{l}\text { A grammar exercise website with lots of } \\
\text { interactive grammar games }\end{array}$ & 4 & 2 & 6 & \\
\hline
\end{tabular}

Another aspect of invisible rubrics is that tasks that are instructions for teachers, such as the teaching notes of item 9 , are considered resources by practitioners, and not as activities. In contrast the quiz sheet of item 11 is strongly identified as an activity because it is something for students to do. This was part of a general feeling that items intended for teachers are resources, while those intended for students are activities. 


\section{Conclusions}

In this paper we have described our attempts to create a teaching and learning repository for the Language Teaching community that learns from the best practices of Web 2.0 sharing sites. Rather than heavyweight pre-designed Learning Objects our repository is built around lightweight sharing of everyday resources, however we included a number of tools that allow users to extend and remix other people's resources, with the intention that this would result in more complex Learning Objects that emerge in the wild, over time and through real use.

Although we have been pleased with the reception the Language Box has received, we have been disappointed with the amount of reuse of resources, and in particular with the low number of activities that have been created.

Through community engagement workshops we have discovered that the problem is not with practitioners abilities to create digital content, nor with the usability of the tool, but in the level of abstraction that we ask of them. Teachers and Lecturers already have a level of abstraction that they are familiar working with, they talk at a business object level about 'exam scripts', 'PowerPoint presentations' and 'lecture notes', and if we require them to further dissect these items and upload the parts separately then this is an additional overhead that confuses some users and is a disincentive to all.

Our intention is to simplify the Language Box data model so that users do not have to make an explicit choice as to whether something is a Resource or an Activity. Instead they will be able to upload anything as a resource, and then create remixes that the system will link with the original. The remixed resource could extend the original material with pedagogical instructions (the equivalent of our existing Activity object) but could also be used to extend material, or to create new versions.

If we want practitioners to use teaching and learning repositories then we not only have to streamline the depositing process and make using the system as easy to use as possible, but we also have to make sure that the object types in the repository match up with people's everyday experiences. Reuse and remixing of educational resources is possible, but only if we support it in the same messy and inconsistent way that it occurs in real life. We cannot all be information engineers; Phantom Tasks do exist, some Rubrics are Invisible, and our systems must be able to support them.

\section{Acknowledgements}

The work described in this paper was part of the JISC funded Faroes project. The authors would like to thank the extended Faroes team, including Julie Watson, Marcus Ramsden and Adam Field, and also the Language Teaching Community. 


\section{References}

1. Bratina T., Hayes D., and Blumsack S. "Preparing Teachers To Use Learning Objects" The Technology Source, November/December 2002

2. Caswell T, Henson S, Jensen M, Wiley D. Open educational resources: Enabling universal education. The International Review of Research in Open and Distance Learning (2008) vol. 9 (1)

3. Diakopoulos N, Luther K, Medynskiy YE, Essa I. The evolution of authorship in a remix society. Proceedings of the eighteenth ACM conference on Hypertext and Hypermedia 133-136, (2007)

4. Downes S., "Learning Objects: Resources for distance education worldwide", The International Review of Research in Open and Distance Learning, Vol 2, No 1 (2001)

5. Hatala M, Richards G, Eap T, Willms J. The interoperability of learning object repositories and services: standards, implementations and lessons learned. Proceedings of the 13th international World Wide Web Conference (2004)

6. Hoermann S. Hildebrandt T, Rensing C, Steinmetz R. ResourceCenter - A Digital Learning Object Repository with an Integrated Authoring Tool Set. Proceedings of World Conference on Educational Multimedia, Hypermedia and Telecommunications 2005 (pp. 3453-3460). Chesapeake, VA: AACE.

7. IEEE LOM, "The learning object metadata standard," IEEE, Tech. Rep., 2005.

8. IEEE LTSC, "IEEE standard for learning technology-learning technology systems architecture (LTSA)," IEEE Std 1484.1-2003 , vol., no., pp. 0_1-97, 2003

9. Klerkx J, Duval E, Meire M. Using information visualization for accessing learning object repositories. Proceedings of the Eighth International IEEE Conference on Information Visualisation (2004)

10. Lamb B. Dr. Mashup or, Why Educators Should Learn to Stop Worrying and Love the Remix. Educause review July/August, 12-24 (2007)

11. Millard, D., Howard, Y., McSweeney, P., Borthwick, K., Arrebola, M. and Watson, J. (2009) The Language Box: Re-imagining Teaching and Learning Repositories. In: International Conference on Advanced Learning Technologies, July 14-18, 2009, Riga, Latvia.

12. Morrison I., and Currie M., "What is a learning object, technically?", Proceedings of WebNet, 2000.

13. Nash SS. Learning objects, learning object repositories, and learning theory: Preliminary best practices for Online Courses. Interdisciplinary Journal of Knowledge and Learning Objects (2005)

14. Neven, F. and Duval, E. 2002. "Reusable learning objects: a survey of LOM-based repositories". In Proceedings of the Tenth ACM international Conference on Multimedia (Juan-les-Pins, France, December 01 - 06, 2002. ACM, New York, NY, 291-294.

15. Schell G.P. and Burns M.. A Repository of e-Learning Objects for Higher Education. EService Journal 53-64 (2002)

16. Thomas A and Rothery A. Online repositories for learning materials: the user perspective. Ariadne, Issue 45 Oct (2005) 